\title{
MOTIVATION STRATEGIES FOR KNOWLEDGE WORKERS: EVIDENCES AND CHALLENGES
}

\author{
Alberto Petroni, Pierluigi Colacino*
}

\begin{abstract}
Many studies have been performed previously to investigate different theories of motivation and, more specifically, how to motivate technical professionals. Through a questionnaire survey carried out on 376 development engineers, identified as "knowledge workers" by managers in their firms, this study identifies what methods are used in industry to motivate these individuals, what works and what does not. While many aspects of standard incentives and reward systems used to motivate technical professionals in general are also motivating for technical visionaries, these results indicate that they are motivated by additional factors not generally discussed in the literature.
\end{abstract}

Keywords: Job satisfaction, Engineering, Motivation, Reward, Skilled workers, R\&D.

\footnotetext{
* Department of Industrial Engineering, University of Parma Viale delle Scienze, I8I/A

43100 - Parma (Italy)

alberto.petroni@unipr.it -Tel.:+390521905850

p.colacino@ied.unipr.it -Tel.: +390521905850
} 


\section{Introduction}

Much has been written on various methods and tools companies use to motivate technical professionals, the group that is often the source of innovation within the organization. More specifically, three main categories of motivational tools and methods used to motivate technical professionals appear in the literature: I) formal structures; 2) incentives, rewards and recognition; and 3) informal management techniques.

Effective reward systems for technical professionals consist of several elements, crossing each of the three motivating categories (Badawy, 1988). Previous research has found that different types of tools are more appropriate, depending upon whether the individual is organizationally oriented (an engineer) or professionally oriented (a scientist).

Motivational structures are formal written policies and procedures in place at organizations. They dictate the way in which a company is formally arranged and organized. Overall, four main types of structures are cited in the literature as motivating technical professionals in industry: I) dual ladders; 2) third-career orientations; 3 ) internal project funding; and 4) prestigious societies. These structures are thought to be more useful in motivating scientists than engineers (Badawy, 1988). A dual ladder -a separate career progression path for technical professionals- motivates them by providing upward career growth while remaining in the technical part of the firm. Technical ladders have been examined and reported in many companies, including Procter and Gamble (Brunner, 200 I), Dow Corning (Lentz, 1990), 3M (Nicholson, 1998), and General Mills (Wolff, 1987). Although expected to be motivational, research shows that many organizations encounter a great deal of difficulty implementing this structure and that the dual ladder by itself is inadequate to motivate technical performance (Allen and R. Katz, 1990), (Allen and R. Katz, 1989), (Epstein, 1985), (Griffin, 1997). Because of the limitations of the dual ladder approach, research into other structural options was conducted, producing a "third-career orientation" (McKinnon, 1987). A third-career orientation is an organizational structure that allows individuals to move from one challenging project to another, as opposed to moving along a more traditional technical or managerial (upward) ladder. Surveys of technical professionals have indicated that a large proportion (greater than one-third) of those probed were interested in pursuing a third-career orientation, where they would move from one challenging project to another and not progress upwards on a ladder (Allen and R. Katz, 1989), (McKinnon, 1987). Shlaes (1991) argues that this (internal funding of innovative ideas) structure is the "way of the future, since it allows innovative employees the time and money to come up with and implement truly innovative ideas." Finally, many firms have created a society or prestigious group to honor their best technical professionals. Examples of this include the Victor Mills Society at Procter and Gamble (Brunner, $200 \mathrm{I}$ ), the IBM Fellows program, and 3M's Carlton Society (Nicholson, 1998). Little has been written about these societies and whether or not technical professionals actually find them motivating.

The second category of motivational methods involves corporate incentives, rewards, and recognition -the traditional focus of human resource staffs for motivating employees. This group contains all monetary and nonmonetary incentives, rewards, and forms of recognition used to motivate technical professionals. Corporate reward and recognition systems are thought to motivate engineers more strongly than scientists (Badawy, 1988). Reward systems encourage outstanding technical contributors to innovate (Brunner, 200I). However, reward systems must fit with the strategy and structure of an organization to be effective and for the organization to be innovative (Agarwal and P. Singh, 1998), (Saleh and C. K.Wang, 1991). If this fit is not present or if the reward structure is not properly implemented, employee needs are not satisfied and demotivation and resentment are likely (Ellis and S. Honig-Haftel, I992), (Koning, Jr., 1993), (Saleh and K. Desai, 1986). Some (Badawy, I982), (Connolly, 1983) argue that extrinsic rewards and recognition are less motivational to technical professionals than intrinsic rewards. This literature suggests that "money for what it can buy is not important to scientists or engineers as money for what it can mean" (Badawy, 1982), (Connolly, 1983). Despite this, other literature (Badawy, 1988), (Sankar et al., I99I) suggests that extrinsic rewards are extremely motivational, enhance creativity, and are valued more than intrinsic rewards. Thus, despite conflicting views on this topic, the common thread is that material needs of individuals must first be satisfied (Badawy, 1988).

Finally, the third category of motivational mechanisms is the informal techniques used by managers and other leaders. This group includes all informal methods that are not part of formal company policy, but that are still implemented by managers or other leaders in an attempt to motivate technical professionals. The majority of the literature, on managing technical professionals, suggests that individuals cannot be motivated to create; instead, they can only be encouraged and enabled through the development of the environment in which they work (Badawy, 1986), (Badawy, 1978), (Kochanski et al., 2003). This literature suggests that motivating creativity is mainly intrinsic in nature, and that it is the manager's job just to create the environment through which this creativity can flourish. Engineers are motivated by more challenging assignments, while scientists are motivated by greater freedom. Both are motivated when managers provide them with increased resources to do their job (Badawy, 1988). 
Despite all the research conducted on motivating technical professionals including surveys investigating the motivation and job effect that certain factors have on technical employees (Allen and R. Katz, 1989), (Sankar et al., 199I), there is still an unaddressed issue: not all technical professionals are the same, and not all groups are motivated by the same things.

After developing a profile of engineers' job expectations and motivational styles, some of the myths and misconceptions in current motivational practices will be discussed. Finally, some guidelines for better motivation and utilization of engineering manpower will also be presented.

In sum, the purpose of this article is to:

- systematically identify the problematic factors relating to current managerial practices in motivating engineers; and

- evaluate their relative contribution to the overall level of engineers' satisfaction.

Finally, the paper discusses some implications and suggests guidelines to management for better motivation and utilization of engineering manpower.

\section{Conceptual model}

Based on the above discussion, a conceptual model has been formulated on which this research is based.

The motivational factors relating to the managerial practices which have an impact on engineers' satisfaction include:

- Managerial policies and supervisory practices;

- Appropriate managerial perception of engineers' status and role within the organization;

- Job-related motivational mechanisms.

Management systems and supervisory practices do not generally reflect an adequate understanding of engineers' expectations and as such are perceived as the first problem area. One example is the managerial practice of administrative engineers supervising engineers. Another source of problems is the criteria used for promotion and career advancement. To date, attention has been given to the problems of potential mismatch between R\&D staff career orientations and available career opportunities (McCormick, 1995). In the study by Hesketh et al. (1992), satisfaction was related to the perceived fit between career path preferences and perceived career path opportunities among senior engineer managers and trainee engineers. Senior respondents' actual career paths (managerial, technical, or those waiting for promotion on to either path) were not well matched to their preferences, with those on paths that were less well matched being less satisfied.

Another source of tension and potential conflict between management and technical professionals is management's perception of engineers and, more specifically, its failure to differentiate between knowledge and non- knowledge employees (Tampoe, 1993).

Managerial practices relating to this aspect include the inappropriate use of traditional techniques of work organization and bureaucratic controls and authority systems.

Thus, management's understated perception of engineers emerges from the failure to differentiate between engineers as knowledge employees and other non-knowledge employees. These practices are dysfunctional and lead to the erosion of the engineers' sense of professionalism.Also, in this area the important theme of the engineers' transition into management can be located. This transition is described as difficult both for those who make it and for those who do not (Roberts and Biddle, 1994). The perceptions of engineers as managers derive from the way the company defines the profession by its required qualifications and the boundary established between it and other technical employees (Canainn, 1995).

The dynamics of the transition into management have been approached from different perspectives. Howard (1983) has studied the basic characteristics that are required for a successful later transition of engineers into management. A primary characteristic is administrative skills, particularly in the areas of planning and organizing, and decision making.

Interpersonal skills are equally important; these include such things as face-to-face leadership, oral communication skills, and making a forceful and likeable personal impact. Intellectual ability is also critical, and research has shown that both verbal and quantitative skills relate to success. Finally, motivation for advancement is a strong determinant of later progress; those who want to succeed are much more likely to do so.As regards managerial skills, on average, engineers come up a little short compared to other functions. Munson and Posner (1979) have investigated the differences in personal value orientations between engineers and managing engineers. Personal values demonstrated significant discriminative and predictive validity in distinguishing managing engineers from non-management engineers. The results of the study suggest that information about personal values might play some role in organizational decisions regarding job placement, promotion, formation of special groups, and in the design of employee motivation and incentive programs. 
A third leverage to increase engineers' motivational potential is through the task itself. The managerial failures with this respect are evident: there are, as stated above, clear indications that engineers are in general underemployed and misutilized.

It would be expected that all these three areas have an impact on engineers' satisfaction. Job satisfaction has many dimensions that can range from career satisfaction, to organizational commitment and job involvement.All these three aspects will be investigated in more detail later on.

Based on this conceptual model, an empirical study was conducted within eleven organizations operating in the food machinery industry in order to:

- Refine and operationalize the conceptual model; and

- Investigate the relative effects of the various factors considered on job satisfaction of development engineers.

\section{Data collection}

Data for the study were obtained from engineers staffed at I I companies in total. The sample group included five large divisions of a worldwide engineering group active in the design, production and marketing of machines and complete lines for the food and tobacco industry and a host of smaller firms manufacturing bottling equipment and food-processing machinery.

The sample was selected randomly from professionals including development engineers, designers and implementers. The respondents came from a variety of organizational units: manufacturing departments, R\&D and engineering groups. Questionnaires were distributed to each participating organization's internal mail. Participation was voluntary and each participant was assured of confidentiality.A cover letter from the management of the respective organization was attached to the questionnaire.

Through the procedure described above, 642 professionals were asked to participate in the study. Of these, 66 currently hold a managerial position and were thus excluded. Exactly 376 professionals returned a complete and usable questionnaire for a satisfactory response rate of 58 percent. The demographic characteristics of the sample are reported in Table I.

\begin{tabular}{l} 
Table I Demographic characteristics of the sample \\
\hline Gender \\
$\begin{array}{l}\text { Male } \\
\text { Female }\end{array}$ \\
$\begin{array}{l}\text { Education } \\
\text { Some graduate school }\end{array}$ \\
$\begin{array}{l}\text { Graduate degree } \\
\text { Age (in years) }\end{array}$ \\
$\begin{array}{l}\text { Organizational tenure } \\
\quad \text { (in years) }\end{array}$ \\
\hline
\end{tabular}

Twenty-one percent of respondents hold a functional technical position without project (either temporary or stable) responsibilities. The remaining respondents hold a position along the technical ladder and are steadily assigned to a project team. Forty percent of the respondents describe their current job as pertaining mainly to strict product design activities (i.e. design and prototyping), 44 percent state that his/her job is related to engineering and implementation aspects, ten percent act mainly as the interface between and in support of either manufacturing or commercial departments, while the remainder have been categorized as "other".

\section{Performance measures}

Job satisfaction is very rarely assessed on a single item but on a number of measures. Therefore, in addition to the elements of the research framework mentioned above, the respondents were asked to rate the level of agreement with 13 statements, on 7-point Likert scales. These 13 measures of job satisfaction can be categorized in line with three underlying dimensions or factors (see Table II), simplifying the interpretation of the results. To this purpose factor analysis provided a three-factor solution (principal component with varimax rotation) that was based on eigenvalues $>I$ and accounted for 63.6 percent of the variance. The dimensions identified have been labeled as "career satisfaction", "job involvement" and "organizational commitment”.

As far as career satisfaction is concerned, satisfaction with promotion rate, pay level, status achieved and progress in achieving career goals were included in the measure.

Responses to the items were averaged to create a career satisfaction score $(=0,93)$. Job involvement refers to the de- 
Table II Performance factors

\begin{tabular}{|c|c|c|c|}
\hline Factors & $\begin{array}{c}\% \text { of } \\
\text { variance }\end{array}$ & Factor components & Load $^{b}$ \\
\hline Career satisfaction & 40.6 & Success achieved in career & 0.90 \\
\hline \multirow{4}{*}{$\alpha=0.93^{c}$} & & Progress in achieving career goals & 0.86 \\
\hline & & Satisfaction with rate of promotion & 0.84 \\
\hline & & Satisfaction with the pay level & 0.63 \\
\hline & & Satisfaction with the status achieved & 0.63 \\
\hline \multirow{4}{*}{$\begin{array}{l}\text { Job involvement } \\
\qquad \alpha=0.80\end{array}$} & 14.7 & Personal goals achieved through the job & 0.80 \\
\hline & & Overlapping between personal life & \\
\hline & & interests and job interests & 0.77 \\
\hline & & Sense of professional pride & 0.68 \\
\hline \multirow[t]{6}{*}{$\begin{array}{l}\text { Organizational commitment } \\
\qquad \alpha=0.70\end{array}$} & 8.3 & $\begin{array}{l}\text { Willingness to put an effort beyond that } \\
\text { required }\end{array}$ & 0.75 \\
\hline & & Loyalty to organization & 0.61 \\
\hline & & $\begin{array}{l}\text { Overlapping between the organization's } \\
\text { and personal values }\end{array}$ & 0.60 \\
\hline & & Pride belonging to the organization & 0.41 \\
\hline & & Agreement with the organization's & \\
\hline & & practices and policies & 0.41 \\
\hline \multicolumn{4}{|c|}{$\begin{array}{l}\text { Notes: } \\
\text { Variance explained for each factor. Total variance explained: } 63.6 \text { percent, Kaiser-Meyer-0lkin }=0.854 \text {. } \\
\text { " Reading of variable on each factor. }\end{array}$} \\
\hline
\end{tabular}

gree to which an employee identifies with his/her present job and the extent to which the job situation is central to the employee's self- identity (Igbaria et al., 1999). This construct was measured by items investigating the personal goals achieved through the job, the level of overlapping between personal life interests and job interests and the sense of professional pride. Responses to the items were averaged to produce a total job involvement score $(=0,80)$.

Finally, organizational commitment can be defined as the employee's identification with a particular organization and his/her desire to maintain membership in the organization. Aspects such as the willingness to put in effort beyond that required, loyalty to the organization, level of overlap between the organization's and the respondent's values, pride in belonging to the organization and agreement with the organization's practices and policies were included. These five items were averaged to obtain an overall index of organizational commitment ( = 0,70).

\section{Results}

After identifying the performance factors and their relative importance in the organizations considered, the second aim of the research was to conceptualize and identify the underlying elements that critically impact on satisfaction. Factor analysis was used to accomplish this (principal components with varimax rotation with a number of factors based on eigenvalues $>$ I).After an initial factor analysis, two variables were found not to load on any factor and were thus removed. The new factor analysis produced five factors that accounted for 66.3 percent of the variance (see Table III). These factors have been labeled (in decreasing order of importance) as:

(I) inadequate reward system;

(2) inadequate understanding of engineers' expectations;

(3) failure to differentiate between professionals and other workers;

(4) lack of task-intrinsic motivation;

(5) inadequate managerial competence and knowledge.

The factor solution is considered to be robust since the factors are easily interpretable from their components and Cronbach alphas confirmed their reliability (all factors have alphas $>0,70$ ).

The next step was to investigate the linkages between the five factors and the three dimensions of performance. Multiple regression analysis was conducted with the latter ones as inde- 
Table III Factor components and loadings

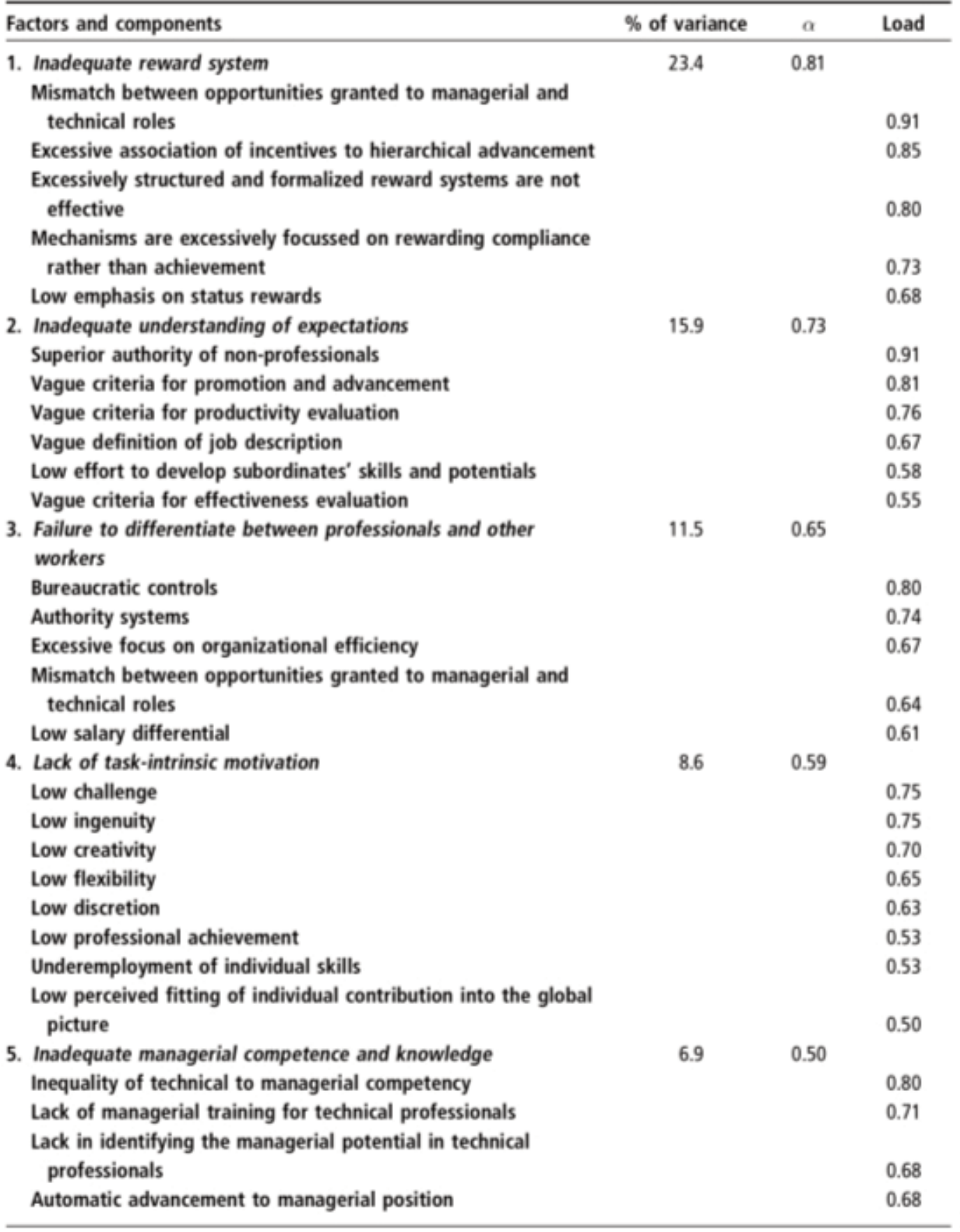

pendent variables.As for the dependent variables, since the objective was to link managerial failures to dissatisfaction, the values complementing seven of the scores given to each of the performance items (since all items were on 7-point Likert scales) were used. Table IV reports the results. All equations are highly significant. As a further check, correlation analysis was also conducted and produced similar results. These results are discussed in the following sections of the article.

\section{Inadequate reward systems}

An inadequate reward system is strongly associated with career dissatisfaction (with the highest regression coefficients of the whole data group), and, to a lower extent, with organiza- 
Table IV Regression coefficients

\begin{tabular}{|c|c|c|c|}
\hline Factors & $\begin{array}{c}\text { Organizational } \\
\text { commitment }\end{array}$ & Career satisfaction & Job involvement \\
\hline Inadequate reward system & $0.11^{\mathrm{a*}}$ & $0.30^{*}$ & - \\
\hline Inadequate understanding of expectations & $0.12^{*}$ & $0.26 * *$ & - \\
\hline \multicolumn{4}{|l|}{ Failure to differentiate between professionals } \\
\hline and other workers & $0.14^{* *}$ & $0.21^{*}$ & $0.11^{*}$ \\
\hline Lack of task-intrinsic motivation & $0.11^{* *}$ & - & $0.25 * *$ \\
\hline Inadequate managerial competence and knowledge & $0.19^{*}$ & - & $0.23^{*}$ \\
\hline Number of factors in equation & $5 / 5$ & $3 / 5$ & $3 / 5$ \\
\hline Adjusted $\mathbf{R}^{2}$ & 0.33 & 0.48 & 0.35 \\
\hline F-value (equation) ${ }^{b}$ & 8.3 & 19.9 & 13.1 \\
\hline \multicolumn{4}{|c|}{$\begin{array}{l}\text { Notes: } \\
\text { a Regression coefficients (standardized betas); * denotes significance at the } 0.1 \text { level; } \\
\cdots \text { denotes significance at the } 0.01 \text { level; 'Significant at } 0.001 \text { for all three equations }\end{array}$} \\
\hline
\end{tabular}

tional commitment. No significant statistical correlation was established between this factor and job involvement. There are a number of problematic areas relating to the adoption of the wrong reward system:

- Rewards for technical and managerial careers have never been equally attractive. Despite strong recognition of the importance of technical excellence in organizations, the managerial career path is perceived as providing the major opportunity for promotion. These findings confirm the results of prior studies (Allen and Katz, 1986; Hesketh et al., 1992) that pinpointed the need to improve the mix of managerial and technical skills in organizations via better job evaluation systems, the use of skills and abilities, job design, and incentive payment for keeping up technical skills.

- Tension between managers and technical professionals is caused by the excessive use of incentives that are almost totally associated with hierarchical advancement.

- Development engineers seem to rely upon their supervisors for recognition rather than upon the organization itself, with little trust in the structural solutions designed to offer opportunities for professional and financial advancement.

- Current reward systems for engineers are also inadequate because they tend generally to reward achievement rather than compliance with management's wishes.

- Analysis has confirmed that engineers do have complaints about the lack of emphasis on status rewards. The work role considered appropriate to an occupational group is determined by its status in the organization. Status depends on how group members are perceived. Hence, being staffed in technical development departments is probably not as prestigious as working in manufacturing and/or commercial departments.

\section{Inadequate understanding of engineers' expectations}

Inadequate understanding of engineers' expectations is strongly associated with career dissatisfaction (with the second highest regression coefficients), and to a lower extent with organizational commitment. In this case too, no significant statistical correlation was established between this factor and job involvement.

One can, thus, affirm that management systems do not reflect a sound understanding of engineers' expectations as professionals. Superior authority exercised by a non- knowledge worker is likely to cause resentment, as it breaches engineers' professional pride.

A second problematic area relates to the general or vague criteria used for promotion and career advancement. Standards of job description and advancement are generally put forward by management in a fuzzy and unclear fashion. Thus if an employee's development is raised by management to a critical criterion of performance evaluation and effectiveness assessment, engineers' concern and dissatisfaction increase. Tension also stems from the fact that firms still put emphasis on measuring engineers' productivity in a traditional way. One major complaint concerns the limited effort made by engineering managers to look for new techniques and modified measures in order to appropriately associate creativity to the traditional measures of productivity. Demotivation may largely hinge upon perceiving the difficulty of measuring individuals' achievement. In this sense, turning to an analysis and development of the individual skills and competencies is much more felt as equitable 
and appropriate. This calls for a shift from productivity evaluation to effectiveness appraisal. But, again, the research has confirmed that little effort is spent by managers to communicate unequivocally what criteria would be used.

\section{Failure to differentiate between professionals and other workers}

The failure to differentiate between professionals and other workers is associated with all three measures of dissatisfaction. One of the major tensions in the engineer-management relationship arises from the use of outdated and old-fashioned management practices, originally conceived mainly for shop floor workers. Examples of these practices include excessively bureaucratic controls and authority systems and disproportionate focus on organizational efficiency. In addition, a small salary differential between knowledge and non- knowledge employees (especially those skilled workers that are not perceived as "professionals" by the engineer) lends further support to the inadequacy of management methods. The importance of salary-related incentives for engineers is that money represents the tangible evidence of how they are rated in the organization. Engineers are particularly sensitive to what they perceive as "unfair" and tend to reject rewards based on any other basis but recognizable professional achievement. Thus a small salary differential with other non-knowledge workers causes a breach of the engineer's sense of self-esteem and professional pride.

\section{Lack of task-intrinsic motivation}

Failure to provide task-related motivational potential is strongly related to job involvement, only weakly associated with organizational commitment and has no impact on career (dis)satisfaction. Updating motivation is primarily intrinsic, but it is constrained (encouraged and/or inhibited) by situational and job-related factors. The task itself is in fact the primary source of motivation, since it provides the necessary excitement to the individual. Engineering managers can leverage the enginee$r$ 's motivational potential by providing adequate elements of challenge, ingenuity, creativity, flexibility and professional achievement. The research has also lent further support to the fact that one of the largest managerial failings is the improper utilization of engineers. There is also evidence of the vast underemployment of engineers in terms of management assignments requiring fewer qualifications than those available. Another important point is that disillusionment arises when engineers perceive their contribution to the overall company activities as highly parceled.

Inadequate managerial competence and knowledge
These points relate to the dissatisfaction felt by many engineers who demand that managers be as competent in their field as the professionals are in technical aspects. In fact, one of the leading factors in motivating engineers is the engineering manager, simply because he or she is the linchpin between management on the one hand and engineers on the other. However, because of their inadequate preparation for careers in management, many competent engineers may become incompetent managers. This problem is exacerbated by the fact that, as has been mentioned above, technical professionals seem to resent being supervised by someone who does not have a technical background.

However, there is substantial evidence which suggests that engineers are generally ill- equipped for managerial careers. This factor has a strong influence on job involvement and has also an impact on organizational commitment. No statistically significant correlation with career satisfaction has been established. As for the managerial failures, current practices of promoting technologists to managerial positions are poor and inadequate and cause a drop in the engineers' sense of professionalism. In particular, the aspects that deserve deeper attention are those concerning the lack of managerial training for technical professionals, the poor effort spent in identifying managerial potential of engineers and the failure of excessively structured and automatic mechanisms to have "the right people at the right place". In short, these failures call for a deeper exploration and understanding of the subject of engineers' transition into management.

\section{Conclusions}

Knowledge workers are a special kind of asset because they increase in value with time, especially when improvements and developments are made. Company policy and reward systems must, therefore, reinforce and support these learning behaviors together with professional enrichment programs.

As far as company policy is concerned, the future of the knowledge organization is dependent on establishing sound recruiting, career planning and placement policies. In particular, there is a need for improved management understanding of the concept of career planning for professional enrichment and growth of engineers. Research on career planning shows that diversity is a critical ingredient in ensuring a beneficial and fulfilling career, especially for older professionals. However, most companies do not provide the necessary chances and incentives for diversity. In short, there is strong evidence suggesting that pushing technical personnel in their late thirties and early 
forties into new fields will enlarge their interests on and off the job, and will have a significant impact on motivation and satisfaction.

From the standpoint of nourishing engineers' vitality and motivation, several strategies can be pursued. These include continuing education, retraining, sabbatical leaves, rotation programs, job transfers, and redesign. For the effective implementation of these strategies, however, management must show its total commitment to continued learning throughout life as a compelling instrument. Incidentally, it is worth noting here that these mechanisms are particularly important for the motivation and technical vitality of older engineers, as they can become bored with the same work after some years.

Placement is another key area because placement of knowledge workers is the route to their productivity. Not only do opportunities have to be provided for people capable of coping with them and of producing results, but technical professionals must also be placed where their skills can be productive.

Designing appropriate placement policies for engineers is thus a vital concern for personnel managers.

Reward systems emphasizing such factors as status, advancement to managerial positions, and authority and influence within the company structure are those most appropriate for engineers. The engineer's status, influence, satisfaction, and productivity are in turn greatly favored by opportunities for participation and involvement in managerial and technical decision making. Salary also becomes an important subject. In view of the importance to engineers of salary and economic incentives, as discussed above, a sound scheme is a necessity. Salary ranges for various engineering classifications should be made clear, with recognition of personal development efforts.

Technical professionals are more productive when they feel they are not a trivial part of the company and that the organization cares about them as individuals. As discussed above, a major antecedent of disillusionment and disappointment for engineers is that current management practices and policies do not incorporate an adequate understanding of their needs and expectations as professionals.

Responsibility, achievement, and contribution are very important elements of motivational mechanisms for engineers.

Engineering managers should, therefore, put more emphasis on these elements, driving their attention toward maximizing the engineer's contribution. This fact obviously has great implications for evaluation criteria that should be more based on jud- ging engineers strictly on the basis of compliance, competence and quality of work. These criteria should include not only performance goals (cost, product features, and efficiency), but also personal and subordinates' development efforts. This would encourage managers to help subordinates develop their skills and potential, and thus enhance subordinates' satisfaction and motivation. It has been shown that there is a significant need for management methods and practices to be designed which allow a better understanding of the differences in work orientations and expectations between engineers, as knowledge workers, and other technical skilled workers. For instance, engineers should be granted the chance to analyze, evaluate, and critique their own performance. Perhaps the most important principle is to enable the knowledge workers to do what they are being paid for. Not to be able to do what one is being paid for infallibly quenches whatever motivation there is.

Another mechanism that has considerable effect on engineers' motivation is the powerful communication content of incentives. In general terms, messages conveyed via incentives tend to override formal verbal communications. Thus, concrete management initiatives are seen to be more powerful than words. Open communications, integrity, and positive reinforcement of company and professional values are certainly key elements in effective motivation.

Another major source of conflict is represented by the low degree of managerial competence of engineering managers with a technical background. This suggests at least three possible remedies. A first principle of general validity is that the poor practice of promoting the most technically competent individual to an administrative position simply due to their technical abilities should be abandoned. Engineering managers should be technically competent enough to obtain the respect of their subordinates, should aspire to supervisory assignments, and should be trained to smooth the transition from "technical competence" to "management capability". Second, more effective selection procedures must be identified and used to identify those promising candidates who are likely to have the right individual profile (orientation to manage, power and interpersonal empathy) for a managerial position.

In addition to proper identification of managerial potential and sound selection, a change in the current continuing educational system for industrial engineers is called for.

The present system fails to develop engineers' managerial skills (as decision makers). There are examples of "in-house" programs being undertaken by several companies worldwide, offering training and coaching activities to bridge the gap from engineering to management. One important principle here is 
that engineering managers should keep in mind that the design of the task environment has a huge impact on learning, growth and motivation. Employees can find creative solutions only when they truly enjoy their work. Managers can also fit the job to the employee's motivational needs by modifying the work situation or organization or by changing their own leadership styles. More than mere positive thinking or generalized confidence in the employee, expectations should be goals tailored to the individual's capabilities.A powerful motivational mechanism is, thus, through job redesign. Work satisfaction is gradually changing its meaning. The significance of meaningful work for engineers is changing due to modifications in cultural and social values.

Meaningful work is not only a question of working out a technical challenge.

Accordingly, jobs need to be redesigned in order to include ingredients of challenge and achievement, and need to be seen to represent a positive contribution to the overall company mission. In short, the concept of job enrichment is quite relevant here and should be used by engineering managers to enhance the motivational potential and productivity of engineers.

\section{References}

AGARWAL, N. and Singh, P. (1998). Organizational rewards for a changing workplace:An examination of theory and practice. Int. J.Technol. Manage., I6(I-3), p.225-238.

ALLEN,T.J. (1988). Distinguishing engineers from scientists. Managing Professionals in Innovative Organizations: A Collection of Readings, R. Katz, Ed. New York.

ALLEN, T. J. and Katz, R. ( 1 989). Managing engineers and scientists: Some new perspectives. Human Resource Management in International Firms, P. Evans, Y. Dos, and A. Laurent, Eds. London, U.K.: Macmillan.

ALLEN,T.J. and Katz, R. (1990). The treble ladder revisited:Why do engineers lose interest in the dual ladder as they grow older?. Proc. Ist Int. Forum Technol. Manage., p.409-426.

ALLEN,T.J. and Katz, R. (1986). The dual ladder: motivational solution or managerial delusion?. R\&D Management, I6(2), p. I8597.

ALLEN,T.J. and Katz, R. (1992).Age, education and technical ladder. IEEETransactions on Engineering Management, 39(3), p.237-45.
ALLEN, T.J. and Katz, R. (1995). The project-oriented engineer: a dilemma for human resource management. $R \& D$ Management, 25(2), p. 129-40.

ARDICHVILI,A., Cardozo, R. and Ray, S. ( 2003).A theory of entrepreneurial opportunity identification and development.J. Bus. Ventur., 18, p. I05- 123.

BAILYN, L. (199I). The hybrid career: an exploratory study of career routes in R\&D. Journal of Engineering and Technology Management, 8(I), p.I-I4.

BRUNNER, G. F. (200I). The IRI medalist's address: The Tao of innovation. Res. Technol. Manage., 44(I), p.45-5I.

CANAINN,A.O. (1995). Herr Ingenieur or the grease monkey? How the managerial prospects of engineers are perceived. Human Resource Management Journal, 5(4), p.74-92.

CHEN, C., Ford, C. and Farris, G. (1999). Do rewards benefit the organization? The effects of reward types and the perceptions of diverse R\&D professionals. IEEE Trans. Eng. Manage., 46(I), p.47-55.

DEBACKERE, K., Buyens, D. and Vandenbossche, T. (1997). Strategic career development for R\&D professionals: lessons from field research. Technovation, I7(2), p.53-62.

FARRIS, G. (1999). Patterns in high-impact innovation. The Dynamics of Innovation: Strategic and Managerial Implications, K. Brockhoff, A. Chakrabarti, and J. Hauschildt, Eds. Berlin, Germany: Springer-Verlag.

FROHMAN, A.L. (1978). Mismatch problems in managing professionals. Research Management, 2 I (4), p.20-5.

GOLDBERG, A.I. and Shenav, Y.A. (I 984). R\&D career paths: their relation to work goals and productivity. IEEE Transactions on Engineering Management, 3 I), p. I I I- I7.

GRIFfiN, A. (1997). PDMA research on new product development practices: Updating trends and benchmarking best practices. J. Product Innov. Manage., I4(6), p.429-458.

GROENVELD, P. (1997). Roadmapping integrates business and technology. Res. Technol. Manage., 40(5), p.48-55.

GUNZ, H. P. (1980). Dual ladders in research:A paradoxical organizational fix. R\&D Manage., I0(3), p. I I3-I I8.

HALL, D. T. and Louis, M. R. (1988). When careers plateau. Res. 
Technol. Manage., 3 I (2), p.4I-45.

HALLENBURG, E.X. (I 970). Dual advancement ladder provides unique recognition for the scientist. Res. Manage., I3(3), p.22 I227.

HESKETH, B., Gardner, D. and Lissner, D. (1992). Technical and managerial career paths: an unresolved dilemma. International Journal of Career Management, 4(3), p.9-I6.

HOWARD,A. (1983). Can Engineers Succeed in General Management? Enhancing Engineering Careers by Fulfilling Individual and Organizational Goals, IEEE, New York, NY), p.76-80.

IGBARIA, M., Kassicieh, S.K. and Silver, M. ( 1999). Career orientations and career success among research, and development and engineering professionals. Journal of Engineering and Technology Management, I6(I), p.29-54.

JOHNSON, D. and Sargeant,A. (1998). Motives for transition: an exploratory study of engineering managers. Human Resource Management Journal, 8(3), p.4I-53.

KERR, J. and Slocum, J.W. (1987). Managing corporate culture through reward system. Acad. Manage. Exec., I(2), p.99-I08.

KOCHANSKI, J., Mastropolo, P. and Ledford, G. (2003). People solutions for R\&D. Res. Technol. Manage., 46(I), p.59-6I, .

KONING,J.W. (1993).Three other R's: Recognition, reward and resentment. Res. Technol. Manage., 36(4), p. 19-29.

LEIFER, R., McDermott, C. M., O'Connor, G. C., Peters, L. S., Rice, M., and Veryzer, R.W. (2000). Radical Innovation: How Mature Companies Can Outsmart Upstarts. Boston, MA: Harvard Business School Press.

LENTZ,W. (1990). Dual ladders become multiple ladders at Dow Corning. Res. Technol. Manage., 33(3), p.28-34.

MARKHAM, S. K. and Aiman-Smith, L. (200I). Product champions: Truths, myths and management. Res. Technol. Manage., 44(3), p.44-50.

MARKHAM, S. K. and Kingon, A. I. (2004). Turning technical advantage into product advantage. In The PDMA ToolBook2 for New Product Development, P. Belliveau, A. GRIFfiN, and S. M. Somermeyer, Eds. Hoboken, NJ:Wiley, ch. 3.

MCCORMICK, K. ( 1995). Career paths, technological obsolescence and skill formation: R\&D staff in Britain and Japan. R\&D
Management, 25(2), p.197-2II.

MILLER, D.B. (1986). Managing Professionals in Research and Development. Jossey-Bass, San Francisco, CA.

MUNSON, J.M. and Posner, B.Z. (1979).The values of engineers and managing engineers. IEEE Transactions on Engineering Management, 26(4), p.94-100.

NICHOLSON, G. C. (1998). Keeping innovation alive. Res. Technol. Manage., 4 I (3), p.34-40.

O'CONNOR, G., Hyland, J. and Rice, M. P. (2004). Bringing radical and other major innovations successfully to market: Bridging the transition from R\&D to operations. In The PDMA ToolBook2 for New Product Development, P. Belliveau, A. Griffin, and S. M. Somermeyer, Eds. Hoboken, NJ:Wiley, ch. 2.

ROBERTS, K. and Biddle, J. (1994). The transition into management by scientists and engineers: a misallocation or efficient use of human resources?. Human Resource Management, 33(4), p.56I-79.

SALEH, S. D. and Desai, K. 1986. Occupational stressors for engineers. IEEE Trans. Eng. Manage., EM-33(I), p.6-II.

SHLAES,A. (1991). Rewarding and stimulating creativity and innovation in technical companies. In Proc. IEEE Conf. Technol. Manage.: New Int. Language, 27(3I), p.609-6I2. Management, Massachusetts Institute of Technology, Cambridge 1989.

STAUDT, E., Bock, J. Muhlemeyer, P. and Kriegesmann, B. (I99I). Incentive systems as an instrument of company innovation management: Results of an empirical investigation in the R\&D sector. Int. J. Technol. Manage., 6(3-4), p.395-4I3.

TAMPOE, M. (1993). Motivating knowledge workers \pm the challenge for the 1990s. Long Range Planning, 26(3), p.49-55.

VOJAK, B.A., Griffin, A. Price, R. L. and Perlov K. 2006. Characteristics of technical visionaries as perceived by American and British industrial physicists. R\&D Manage., 36(I), p. I7-26.

WOLFF,W.E. (1987). Revisiting the dual ladder at General Mills. Res.Technol. Manage., 30(3), p.8-12. 


\section{About the Authors}

Prof.Alberto Petroni received his Degree in Business Administration from Bocconi University of Milano and his Ph.D. in Industrial Engineering and Management from the University of Padova. He holds the chair of Business Administration at the Faculty of Engineering at the University of Parma, where he is serving as Director of Industrial Engineering and Management course. He has been the recipient of several research contracts from private firms. His research activities mainly concern management of technological innovation and industrial marketing.

Dr. Pierluigi Colacino graduated in 2006 in Industrial Engineering and Management at the University of Parma where he currently is a Ph. D. Student in Economic and Managerial Engineering. His research interests mainly relate to management of technology and career development. 